\title{
Produksi Bahan Bakar Minyak dari Pirolisis Pelet Hydropulper Reject Industri Kertas
}

\author{
Syamsudin $^{1 *}$, Reza Bastari Imran Wattimena ${ }^{1}$, Ibrahim Syaharuddin², Andri Taufick Rizaluddin ${ }^{1}$, \\ Yusup Setiawan ${ }^{1}$ \\ ${ }^{1}$ Balai Besar Pulp dan Kertas, Jl. Raya Dayeuhkolot No. 132, Bandung, Indonesia \\ ${ }^{2}$ Institut Teknologi Nasional, Jl. PH.H. Mustofa No.23, Bandung, Indonesia
}

Diterima : 12 November 2020, Revisi akhir : 24 Desember 2020, Disetujui terbit : 30 Desember 2020

\section{Production of Oil Fuel From Pyrolysis of Hydropulper Reject Pellet from Paper Industry}

\begin{abstract}
Waste paper consumption in Indonesian paper industries reached 6,598,464 tons/year and produced hydropulper reject about 5-10\% of waste paper. Pyrolysis of hydropulper reject from the paper industry for bio-oil production has been investigated. Hydropulper reject consists of $20 \%$ fiber and $80 \%$ plastic (High Density Polyethylene, HDPE $>90 \%$ ). This solid material has potential to be converted into oil fuel through pyrolysis. This study aims to investigate the pyrolysis of hydropulper reject pellets for bio-oil as fuel oil production. After being separated from the metals, hydropulper reject was dried, shredded, and shaped into pellets with $10 \mathrm{~mm}$ diameter and 20-30 $\mathrm{mm}$ length. The pellets had calorific value of $29.30 \mathrm{MJ} / \mathrm{kg}$ (dried based, db) with volatile matter $84.84 \%(\mathrm{db})$. The pellets were pyrolized with a combustion-pyrolysis combination reactor. The product was combustible bio-oil as much as $\pm 40 \%$ of feedstock and had calorific value of $77.79 \mathrm{MJ} / \mathrm{kg}$. Estimated electricity generated from syngas utilization about $1.08 \mathrm{kWh} / \mathrm{kg}$.
\end{abstract}

Keywords: hydropulper reject, pyrolysis, bio-oil, syngas, electricity

\begin{abstract}
Abstrak
Konsumsi kertas bekas di industri kertas Indonesia mencapai 6.598 .464 ton/tahun dan menghasilkan hydropulper reject sebesar 5-10\% dari kertas bekas yang digunakan. Penelitian pirolisis hydropulper reject dari industri kertas untuk produksi bio-oil telah dilakukan. Tipikal limbah hydropulper reject terdiri dari 20\% serat dan 80\% plastik (High Density Polyethylene, HDPE $>90 \%$ ). Bahan padat tersebut berpotensi dikonversi menjadi bahan bakar minyak melalui proses pirolisis. Penelitian ini bertujuan mengevaluasi pirolisis pelet hydropulper reject untuk produksi bio-oil sebagai bahan bakar minyak. Setelah dipisahkan dari logam, hydropulper reject dikeringkan, dicacah, dan dibentuk menjadi pelet berdiameter $10 \mathrm{~mm}$ dan panjang 20-30 mm. Nilai kalor pelet hydropulper reject mencapai $29,30 \mathrm{MJ} / \mathrm{kg}$ (dried based, db) dengan kadar zat terbang 84,84\% (db). Pelet hydropulper reject dipirolisis dengan reaktor kombinasi pembakaran-pirolisis. Produk yang dihasilkan berupa bio-oil mampu bakar sebanyak $\pm 40 \%$ bahan baku dengan nilai kalor $77,79 \mathrm{MJ} / \mathrm{kg}$. Perkiraan listrik yang dapat dihasilkan dari pemanfaatan syngas sebesar $1,08 \mathrm{kWh} / \mathrm{kg}$ hydropulper reject.
\end{abstract}

Kata kunci: hydropulper reject, pirolisis, bio-oil, syngas, listrik 


\section{Pendahuluan}

Kebijakan Energi Nasional (KEN) yang menjadi program pemerintah seperti tertuang dalam Peraturan Presiden No. 79/2014 mengamanatkan untuk pemanfaatan energi baru dan terbarukan pada tahun 2025 dengan pangsa sebesar 23\% terhadap bauran energi primer dan meningkat menjadi $31 \%$ pada tahun 2050 (BPPT, 2019). Saat ini konsumsi energi final masih didominasi oleh penggunaan bahan bakar minyak dengan pangsa sebesar 50\% dengan pengguna energi terbesar adalah sektor transportasi (43\%), sektor industri (35\%), dan sektor rumah tangga (14\%) (BPPT, 2019). Cadangan minyak bumi Indonesia pada tahun 2018 sebesar 7,51 miliar barel. Cadangan ini mengalami penurunan $0,27 \%$ terhadap tahun 2017. Serupa dengan minyak bumi, cadangan gas bumi pada tahun 2018 sebesar 135,55 TSCF (trillions of standard cubic feet). Cadangan ini juga mengalami penurunan sebesar 5,02\% terhadap tahun 2017 (BPPT, 2019). Penurunan cadangan minyak bumi dan gas bumi mendorong perlunya peningkatan efisiensi dan diversifkasi sumber energi supaya ketahanan energi tetap terjaga. Potensi energi baru dan terbarukan di Indonesia cukup besar mengingat letak geografisnya di daerah tropis, dengan variasi jenis yang sangat beragam.

Salah satu bahan bakar baru yang menarik perhatian adalah hydropulper reject dari industri kertas. Hydropulper reject adalah limbah yang dikeluarkan dari proses repulping pada tahap awal proses pembuatan pulp dari kertas bekas. Hydropulper reject sebagian besar terdiri dari bundel serat, foil, dan plastik polimer dengan jumlah tergantung pada kualitas kertas bekas yang digunakan sebagai bahan baku (Gavrilescu, 2008; Monte et al., 2009). Pada saat ini, terdapat empat puluh lima industri kertas di Indonesia yang beroperasi menggunakan bahan baku kertas bekas (Indonesian Pulp and Paper Association, 2011). Asosiasi Pulp dan Kertas Indonesia (IPPA) melaporkan bahwa konsumsi kertas bekas untuk produksi kertas mencapai jumlah 6.598.464 ton per tahun (Indonesian Pulp and Paper Association, 2011). Sebagian besar industri kertas Indonesia menghasilkan limbah hydropulper reject sebesar 5-10\% dari kertas bekas yang digunakan, atau sekitar 329.923 hingga 659.846 ton limbah hydropulper reject kering udara per tahun (Gavrilescu, 2008).

Hydropulper reject dapat dikonversi menjadi bentuk energi melalui konversi termal seperti pembakaran, gasifikasi, dan pirolisis. Proses pirolisis adalah pilihan yang efektif dan ramah lingkungan untuk pengolahan limbah hydropulper reject untuk mendapatkan bahan bakar cair yang disebut sebagai minyak pirolitik atau bio-oil berkualitas yang dapat memiliki sifat serupa dengan bahan bakar minyak bumi yang biasa digunakan (Casoni et al., 2015; Fadhil, 2017; Fadhil, Alhayali and Saeed, 2017). Keunggulan teknologi pirolisis dibandingkan dengan insinerator yang digunakan untuk pengolahan limbah hydropulper reject, antara lain emisi lebih bersih, tidak diperlukan peralatan pengendalian polusi, area lebih kecil, operasi lebih, desain fleksibel karena bentuk modular, konsumsi energi rendah, abu atau inert material sebagai residu dapat didaur ulang khususnya untuk metal, sesuai untuk fasilitas pengolahan skala kecil dan sekitar tempat pembuangan limbah padat, memberikan solusi atas penolakan teknologi insinerasi, yang ditengarai menghasilkan dioksin dan furans.

Pembuatan pelet dengan kadar air bahan $<15 \%$ dapat menghasilkan pelet hydropulper reject yang kompak tidak mudah pecah dengan nilai kalor tinggi (30 - 37 MJ/kg), rendah kadar abu dan kadar sulfur (Setiawan et al., 2016). Pirolisis non-katalitik terhadap plastik HDPE pada suhu $450-470^{\circ} \mathrm{C}$ dan memperoleh hasil produk cair yang relatif tinggi yaitu $78,7 \%$ dan gas $17,8 \%$, sedangkan pirolisis menggunakan katalis zeolit memberikan hasil gas tertinggi mencapai $95,7 \%$ dan produk cair 2,4\% (Zeaiter, 2014). Penelitian pirolisis terhadap pulper reject telah dilakukan menggunakan katalis klinoptilolit aktif dan meerschaum untuk produksi bahan bakar minyak pirolitik menghasilkan cairan tertinggi $(61,4 \%)$ dan arang (32,19\%) diperoleh menggunakan klinoptilolit $15 \%$ dan meerschaum $5 \%$, sedangkan hasil gas tertinggi $(21,44 \%)$ diperoleh melalui proses nonkatalitik (Salan, Alma and Altuntaş, 2019). Park et al. (2012) melakukan percobaan pirolisis RPF (Refuse derived paper and plastics densified Fuel) menggunakan tungku tabung dalam lingkungan nitrogen pada kondisi non-isotermal (suhu maksimum: $400^{\circ} \mathrm{C}, 600^{\circ} \mathrm{C}$, dan $800^{\circ} \mathrm{C}$ ). Pirolisis RPF menghasilkan cairan (50\%), padatan $(15 \%)$, dan gas $(35 \%)$ pada $400^{\circ} \mathrm{C}$; cair $(53 \%)$, padatan $(10 \%)$, dan gas $(37 \%)$ pada $600^{\circ} \mathrm{C}$; dan cair $(41 \%)$, padatan $(6 \%)$, dan gas $(53 \%)$ pada $800^{\circ} \mathrm{C}$ dengan senyawa utama dari cairan direpresentasikan sebagai kelas benzena dan stirena pada semua suhu percobaan. 
Penelitian ini bertujuan mengevaluasi pirolisis pelet hydropulper reject dari industri kertas untuk produksi bio-oil sebagai bahan bakar minyak. Ruang lingkup penelitian dibatasi pada karakterisasi pelet, uji coba pirolisis pelet, karakterisasi bio-oil, dan perhitungan perkiraan listrik yang dihasilkan.

\section{Bahan dan Metode}

\section{Bahan}

Hydropulper reject dengan kadar air 40$50 \%$ diambil dari alat hydropulper pada proses produksi kertas medium bergelombang dari kertas daur ulang di industri kertas. Potongan kayu bakar sebanyak $\pm 7 \mathrm{~kg}$ dan LPG (Liquefied Petroleum Gas) disediakan untuk keperluan start up pada proses pemanasan reaktor pirolisis.

\section{Alat}

Peralatan untuk pembuatan pelet berupa mesin pencacah kapasitas $100 \mathrm{~kg} / \mathrm{hari}$ dan mesin pelet tipe vertikal flat die dengan plat cetakan yang berlubang-lubang berdiameter $10 \mathrm{~mm}$ kapasitas $100 \mathrm{~kg} /$ hari. Peralatan untuk pirolisis berupa reaktor kombinasi pembakaran-pirolisis skala $100 \mathrm{~kg} /$ batch. Peralatan pendukung lainnya yaitu, kondensor syngas hasil pirolisis, pendingin gas pembakaran, separator, dan blower. Diagram skematik dari sistem reaktor pirolisis ditampilkan dalam Gambar 1.


Keterangan:
1. Reaktor
2. Blower
3. Kondensor pirolisis

4. Tiang penyangga

5. Pendingin gas

6. Separator

Gambar 1. Rangkaian Reaktor Pirolisis

\section{Metode}

Hydropulper reject diumpankan ke dalam reaktor pirolisis dalam bentuk pelet. Proses pembuatan pelet dilakukan dengan tahapan sebagai berikut:

1. Hydrapulper reject disortir untuk memisahkan logam dan pengotor lainnya secara manual;

2. Hydropulper reject dikeringkan dengan panas matahari sampai kadar air $\pm 10 \%$;

3. Hydrapulper reject kering dan bebas logam dicacah dengan mesin pencacah menjadi bentuk cacahan dengan ukuran $\pm 4 \mathrm{~mm}$;

4. Cacahan hydrapulper reject kering (kadar air $\pm 10 \%$ ) dibentuk menjadi pelet menggunakan mesin pelet tipe flat die. Pelet yang dihasilkan memiliki diameter $\pm 10 \mathrm{~mm}$ dan panjang 10 $15 \mathrm{~mm}$.

5. Pelet digunakan sebagai umpan proses pirolisis.

Diagram percobaan pirolisis pelet hydropulper reject terdapat dalam Gambar 2. Pelet hydropulper reject sebanyak $\pm 50 \mathrm{~kg}$ diumpankan ke dalam reaktor pirolisis. Untuk proses start up, potongan kayu sebanyak $\pm 7 \mathrm{~kg}$ diumpankan ke dalam reaktor pembakaran yang berada di bagian luar reaktor pirolisis. Ketika proses produksi sudah stabil, umpan reaktor pembakaran dapat diganti dengan arang hasil pirolisis. Proses pirolisis dipertahankan pada suhu $900-950^{\circ} \mathrm{C}$. Panas yang diperlukan untuk proses pirolisis diambil dari panas pembakaran dari reaktor pembakaran.

Gas hasil pirolisis dikondensasi menjadi biooil menggunakan kondenser. Proses kondensasi menjadi cairan bio-oil dilakukan dengan rekayasa aliran gas. Gas yang tidak terkondensasi dapat diumpankan sebagai bahan bakar genset listrik untuk menghasilkan listrik.

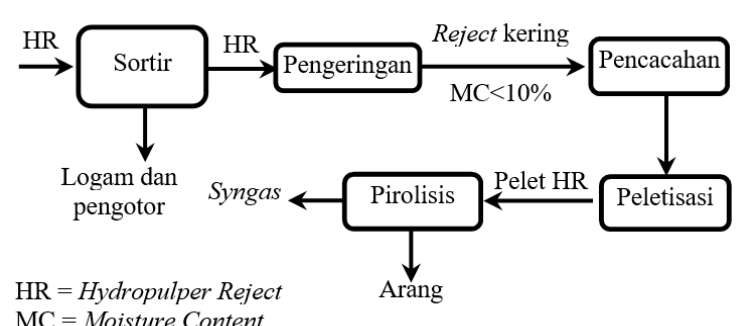

Gambar 2. Alur Percobaan Pirolisis Pelet Hydropulper Reject 


\section{Analisis}

Karakterisasi jenis plastik yang terdapat dalam hydropulper reject dilakukan menggunakan metode Exler (Exler, 2008). Jenis plastik diidentifikasi menggunakan tahapan uji air dan uji isopropil alkohol.

Karakterisasi pelet dilakukan melalui analisis proksimat, ultimat, dan nilai kalor. Analisis proksimat meliputi kadar air inherent (ASTM D3173 - Standard Test Method for Moisture in the Analysis Sample of Coal and Coke), abu (ASTM D3174 - Standard Test Method for Ash in the Analysis Sample of Coal and Coke from Coal), zat terbang (ISO 562:2010 - Hard coal and coke - Determination of volatile matter), dan karbon padat (by difference). Analisis ultimat meliputi kadar karbon, hidrogen, nitrogen (ASTM D5373 - Standard Test Methods for Determination of Carbon, Hydrogen and Nitrogen in Analysis Samples of Coal and Carbon in Analysis Samples of Coal and Coke), total sulfur (ASTM D4239 - Standard Test Method for Sulfur in the Analysis Sample of Coal and Coke Using HighTemperature Tube Furnace Combustion), dan oksigen (by difference). Nilai kalor dianalisis dengan standar ASTM D5865 - Standard Test Method for Gross Calorific Value of Coal and Coke.

Mutu bio-oil yang dihasilkan diuji melalui analisis nilai kalor menggunakan bomb calorimeter. Komposisi syngas dilakukan menggunakan kromatografi gas. Mutu bio-oil hasil penelitian dibandingkan dengan mutu biooil dari penelitian lain, diesel komersial, dan ASTM D7544-12 - Standard Specification for Pyrolysis Liquid Biofuel.

\section{Hasil dan Pembahasan}

\section{Hydropulper Reject Industri Kertas}

Hydropulper reject terdiri dari serat $20 \%$ dan plastik $80 \%$. Karakterisasi plastik menunjukkan $>90 \%$ plastik yang terdapat dalam hydropulper reject berupa plastik jenis HDPE. Komposisi ini berbeda dengan hasil penelitian oleh Setiawan et al. (2014) yang menyebutkan bahwa komponen hydropulper reject terdiri dari serat $50,75 \%$ dan plastik 49,25\% dengan kandungan plastik HDPE $>99 \%$. Perbedaan ini terjadi karena komposisi hydropulper reject dipengaruhi oleh kualitas kertas bekas yang digunakan sebagai bahan baku dan efisiensi alat hydropulper dalam memisahkan serat dan reject. Komposisi ini menunjukkan bahwa hydropulper reject sebagian besar terdiri dari plastik HDPE. HDPE merupakan salah satu jenis plastik yang tersusun dari hidrokarbon yang terdiri dari karbon dan hidrogen, mirip dengan bahan bakar hidrokarbon seperti gas minyak cair (LPG), bensin dan solar. Pembakaran plastik HDPE lebih ramah lingkungan daripada senyawa plastik lainnya (misalnya Polyvinyl Chloride, PVC) karena bahan ini terbuat dari hidrokarbon rantai lurus yang bebas dari halogen. Hasil penelitian co-pembakaran HDPE dan biomassa menunjukkan tidak terjadi peningkatan konsentrasi dioksin dan partikulat dengan penambahan HDPE (Colapicchioni et al., 2020). Bagian penting lain dari hydropulper reject yaitu serat selulosa dan berbagai bahan berbasis biomassa dalam jumlah kecil.

Nilai proksimat, ultimat, dan nilai kalor hydropulper reject terdapat dalam Tabel 1. Nilai kalor hydropulper reject mencapai 29,30 MJ/kg (db), lebih tinggi dari nilai kalor batubara pada umumnya. Nilai kalor hydropulper reject semakin meningkat dengan bertambahnya jumlah plastik, dimana plastik memiliki nilai kalor lebih tinggi dibandingkan biomassa (Salan, Alma and Altuntaş, 2019). HDPE memiliki nilai kalor LHV 43,01 MJ/kg (Chattopadhyay et al., 2016).

Hydropulper reject memiliki kandungan zat terbang tinggi, mencapai $84,84 \%(\mathrm{db})$. Zat terbang secara signifikan mempengaruhi perolehan produk bio-oil. Kandungan zat terbang tinggi menyebabkan peningkatan hasil bio-oil (Abnisa, Arami-Niya, et al., 2013). Asadullah et al. (2008) meneliti bahwa zat terbang biasanya diubah menjadi bio-oil setelah kondensasi. Dengan

Tabel 1. Nilai Proksimat dan Nilai Kalor Pelet Hydropulper Reject Industri Kertas

\begin{tabular}{|c|c|c|c|}
\hline Parameter & Nilai & Parameter & Nilai \\
\hline Proksimat $(\mathrm{db})$ & & $\begin{array}{l}\text { Ultimat } \\
(\mathrm{db}) \text { : }\end{array}$ & \\
\hline $\mathrm{Abu}$ & $9,66 \%$ & $\mathrm{C}$ & $64,17 \%$ \\
\hline \multirow{3}{*}{$\begin{array}{l}\text { Zat terbang } \\
\mathrm{K} \text { a r b o n } \\
\text { padat }\end{array}$} & $84,84 \%$ & $\mathrm{H}$ & $9,89 \%$ \\
\hline & $5,49 \%$ & $\mathrm{O}$ & $16,06 \%$ \\
\hline & & $\mathrm{N}$ & $0,11 \%$ \\
\hline $\begin{array}{l}\text { Nilai kalor } \\
(\mathrm{HHV}, \mathrm{db})\end{array}$ & $29,30 \mathrm{MJ} / \mathrm{kg}$ & S & $0,10 \%$ \\
\hline
\end{tabular}


demikian, dapat disimpulkan bahwa semakin besar jumlah zat terbang dalam hydropulper reject maka semakin banyak jumlah bio-oil yang dapat dihasilkan. Kadar karbon padat pada hydropulper reject cukup rendah, yaitu 5,49\% (db). Pirolisis material dengan kadar karbon padat rendah akan menghasilkan sedikit arang. Kadar abu mencapai 9,66\% (db). Kandungan abu mempengaruhi terjadinya proses slagging dan fouling pada dinding reaktor dan pipa-pipa saluran gas selama proses pirolisis.

\section{Pirolisis Pelet Hydropulper Reject}

Perolehan bio-oil dari pirolisis hydropulper reject mencapai 40\% (Tabel 2). Hasil ini lebih rendah dari perolehan bio-oil dari pirolisis biomassa lain, kemungkinan disebabkan oleh suhu pirolisis yang tinggi dan proses kondensasi yang belum maksimal sehingga masih ada gas kondensabel yang terbawa aliran bersama gas non-kondensabel lainnya. Kualitas produk biooil hasil penelitian ini dibandingkan dengan hasil penelitian lain, diesel komersial, dan ASTM D7544-12 terdapat dalam Tabel 3.

Nilai kalor adalah parameter kritis untuk menentukan mutu bahan bakar. Nilai kalor sangat dipengaruhi oleh komposisi unsur, khususnya kandungan oksigen, serta sifat lain seperti kadar air (Salan, Alma and Altuntaş, 2019). Hasil karakterisasi bio-oil menunjukkan nilai kalor yang tinggi mencapai $77,79 \mathrm{MJ} / \mathrm{kg}$, lebih tinggi dari nilai kalor diesel komersial. Nilai kalor ini diperoleh setelah dilakukan pemisahan air dari bio-oil. Kadar air bio-oil masih cukup tinggi, yaitu $21,87 \%$, paling tinggi dibandingkan biooil lainnya pada Tabel 3. Kadar air yang tinggi menurunkan viskositas, nilai pemanasan, laju pembakaran, dan suhu nyala adiabatik selama proses pembakaran. Menurut data literatur, kandungan air dari minyak yang diperoleh dari sumber biomassa biasanya bervariasi dalam kisaran $15-35 \%$ berat (Salan, Alma and Altuntaş, 2019). Pemisahan air dari bio-oil diperlukan untuk meningkatkan kualitasnya sebagai bahan bakar minyak.

Tabel 2. Perbandingan Perolehan Bio-Oil dari Pirolisis Hasil Penelitian dengan Literatur

\begin{tabular}{clcccc}
\hline No & Biomassa & Suhu & Katalis & Bio-oil & Ref. \\
\hline 1. & Pulper reject & $550^{\circ} \mathrm{C}$ & Klinoptilolit, meerschaum & $61,4 \%$ & 1 \\
& & $400^{\circ} \mathrm{C}$ & - & $50,0 \%$ & \\
2. & RPF & $600^{\circ} \mathrm{C}$ & - & $53,0 \%$ & 2 \\
& & $800^{\circ} \mathrm{C}$ & - & $41,0 \%$ & \\
3. & RPF & $500^{\circ} \mathrm{C}$ & - & & 3 \\
4. & HDPE & $450-470^{\circ} \mathrm{C}$ & - & $78,7 \%$ & 4 \\
5. & Hydropulper reject & $950^{\circ} \mathrm{C}$ & Zeolit & $2,4 \%$ & 5 \\
\hline
\end{tabular}

Sumber: 1. Salan, Alma and Altuntaş (2019); 2. Park et al. (2012); 3. Hwang, Kobayashi and Kawamoto (2014); 4. Zeaiter (2014); 5. Penelitian ini

Tabel 3. Perbandingan Mutu Bio-Oil Hasil Pirolisis

\begin{tabular}{lccccc}
\hline Karakteristik & 1 & 2 & 3 & 4 & 5 \\
\hline Nilai kalor $(\mathrm{MJ} / \mathrm{kg})$ & $13-40$ & $21-46$ & $42-46$ & min. 15 & 77,79 \\
Kadar air $(\%$ berat) & $15-35$ & $0-15$ & $0-0,02$ & maks. 30 & 21,87 \\
Viskositas $40^{\circ} \mathrm{C}(\mathrm{cSt})$ & $10-175$ & $5-30$ & $2-5$ & maks. 125 & 3,29 \\
Massa jenis $(\mathrm{g} / \mathrm{mL})$ & $0,9-1,3$ & $1-1,25$ & $0,81-0,87$ & $1,1-1,3$ & 0,8205 \\
$\mathrm{pH}$ & $1,8-5,5$ & n.d.a & $5-6$ & n.d.a & $4-5$ \\
\hline
\end{tabular}

Keterangan: 1. Basis biomassa (Mohan, Pittman and Steele, 2006; Vamvuka, 2011); 2. Basis campuran biomassa-plastik (Abnisa, Wan Daud, et al., 2013; Chen et al., 2016; Xue et al., 2015); 3. Diesel komersial (Chen et al., 2016; Miandad et al., 2017); 4. ASTM D7544-12; 5. Penelitian ini.

n.d.a = data tidak tersedia 


\section{Perkiraan Produksi Listrik dari Syngas}

Perkiraan produk listrik yang dapat dihasilkan ketika syngas yang dikonversi menjadi listrik sebagai berikut:

- Satu kg hydropulper reject menghasilkan $2 \mathrm{~m}^{3}$ syngas (diperkirakan berdasarkan hasil pengukuran laju gas).

- Komposisi syngas hasil pirolisis ditampilkan dalam Tabel 4.

Nilai kalor syngas diperkirakan dengan perhitungan nilai kalor dari $\mathrm{H}_{2}, \mathrm{CH}_{4}$ dan $\mathrm{CO}$, yaitu $11,09 \mathrm{MJ} / \mathrm{kg}$ hydropulper reject. Asumsi efisiensi pembangkit listrik sebesar 35\%, maka satu $\mathrm{kg}$ hydropulper reject dapat menghasilkan energi listrik sebesar sebanyak 1,08 kWh.

\section{Neraca Massa, Konsumsi, dan Produksi Energi}

Gambar 3 menyajikan neraca massa pada pembuatan dan pirolisis pelet hydropulper reject $50 \mathrm{~kg} /$ batch. Bahan baku hydropulper reject sebanyak 123,8 kg dengan kadar air 50\% mengandung logam dan pengotor sebanyak $\pm 10 \%$. Logam dan pengotor ini dipisahkan sebelum diproses lebih lanjut. Proses pengeringan mengunakan panas matahari selama dua hari dapat menurunkan kadar air bahan baku menjadi $\pm 10 \%$ dengan menguapkan air sebanyak 49,5 kg. Mesin pencacah dan mesin pelet, masing-masing memiliki efisiensi $\pm 95 \%$ dan $\pm 85 \%$. Efisiensi ini dihitung dari jumlah produk yang dihasilkan dibandingkan dengan bahan baku yang diproses oleh mesin tersebut. Proses pirolisis menghasilkan $\pm 20 \mathrm{~kg}$ bio-oil $(40 \%)$ dan $\pm 3,5 \mathrm{~kg}$ arang (7\%). Jumlah syngas yang dihasilkan dihitung dari selisih antara jumlah pelet hydropulper reject yang masuk ke reaktor pirolisis dengan jumlah bio-oil dan arang yang dihasilkan.

Tabel 4. Komposisi Syngas Hasil Pirolisis

\begin{tabular}{clcc}
\hline No. & Gas & $\begin{array}{c}\text { Nilai kalor } \\
(\mathrm{kJ} / \mathrm{mol})^{*}\end{array}$ & Komposisi \\
\hline 1. & $\mathrm{H}_{2}$ & 241,82 & $20,0 \%$ \\
2. & $\mathrm{CO}$ & 283,00 & $19,0 \%$ \\
3. & $\mathrm{CH}_{4}$ & 802,62 & $1,5 \%$ \\
4. & $\mathrm{CO}_{2}$ & & $12,0 \%$ \\
5. & Gas lain & & $47,5 \%$ \\
\hline
\end{tabular}

*Sumber: Green and Perry (2008)

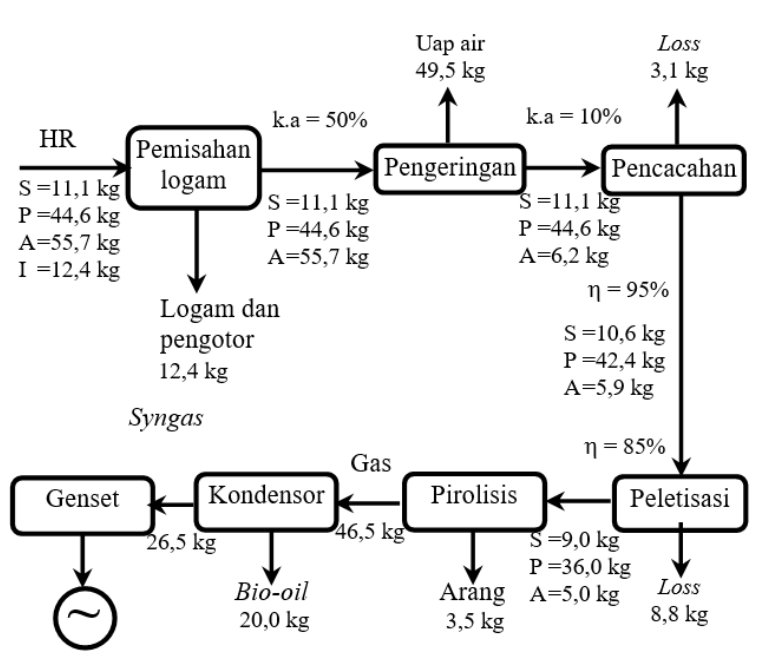

$\mathrm{S}=$ serat; $\mathrm{P}=$ plastik; $\mathrm{A}=$ air $\mathrm{I}=$ logam dan pengotor; $\mathrm{k} . \mathrm{a}=\mathrm{kadar}$ air

Gambar 3. Neraca Massa Pirolisis Pelet Hydropulper Reject

Tabel 5. Peralatan Pengguna Listrik

\begin{tabular}{clcc}
\hline No. & Pengguna Listrik & $\begin{array}{c}\text { Daya } \\
(\mathrm{kW})\end{array}$ & $\begin{array}{c}\text { Konsumsi } \\
\text { Listrik }(\mathrm{kWh})\end{array}$ \\
\hline 1. & Mesin pencacah & 3,2 & 47,6 \\
2. & Mesin pelet & 5,67 & 80,0 \\
3. & Blower & 0,36 & 0,5 \\
& Total & & 128,1 \\
\hline
\end{tabular}

Proses produksi dan pirolisis pelet hydropulper reject menggunakan beberapa peralatan yang mengkonsumsi listrik, yaitu mesin pencacah, mesin pelet, dan blower. Daya dan konsumsi listrik dari masing-masing peralatan tersebut ditampilkan pada Tabel 5. Mesin pelet menggunakan bahan bakar solar dengan konsumsi setara dengan listrik $80 \mathrm{kWh}$. Kebutuhan listrik secara keseluruhan mencapai $128,1 \mathrm{kWh}$.

Gambar 4 menyajikan konsumsi dan produksi energi pada proses pembuatan dan pirolisis pelet hydropulper reject. Energi masuk dari bahan baku pelet hydropulper reject sebesar 366,4 kWh. Pirolisis merupakan reaksi endotermik yang membutuhkan sumber panas. Panas tersebut dipenuhi dengan pembakaran kayu yang menghasilkan panas setara $36,6 \mathrm{kWh}$. Pirolisis menghasilkan bio-oil setara 432,2 kWh dan syngas setara $154,0 \mathrm{kWh}$. Secara teoritis, jika syngas tersebut diumpankan ke mesin genset yang memiliki efisiensi 35\%, maka dapat menghasilkan listrik sebesar 53,9 kWh. Kebutuhan energi start-up, seperti LPG untuk menyalakan reaktor 




Gambar 4. Konsumsi dan Produksi Energi pada Pirolisis Pelet Hydropulper Reject

pembakaran hingga mencapai suhu yang dibutuhkan belum diperhitungkan.

\section{Kesimpulan}

Nilai kalor pelet hydropulper reject cukup tinggi sehingga sangat berpotensi sebagai bahan bakar alternatif. Pemanfaatan pelet hydropulper reject melalui pirolisis pada suhu $950^{\circ} \mathrm{C}$ dapat menghasilkan produksi bahan bakar minyak bio-oil sebanyak $\pm 40 \%$ bahan baku dengan nilai kalor $77,79 \mathrm{MJ} / \mathrm{kg}$. Perkiraan listrik yang dapat dihasilkan dari pemanfaatan syngas yaitu $1,08 \mathrm{kWh} / \mathrm{kg}$ hydropulper reject. Perkiraan produk listrik yang dihasilkan dari pemanfaatan syngas setelah dikurangi kebutuhan listrik untuk proses menunjukkan surplus listrik.

\section{Saran}

Produk bio-oil dan syngas masih memerlukan uji coba lebih lanjut pada penggunaannya dalam motor bakar. Penggunaan bio-oil untuk substitusi solar dalam motor bakar kemungkinan dapat menyebabkan korosi dan pembentukan kerak. Penggunaan syngas untuk bahan bakar genset listrik memerlukan modifikasi pada sistem ruang bakar.

\section{Ucapan Terima Kasih}

Penelitian ini didanai oleh Direktorat Pengembangan Teknologi Industri, Kementerian Riset, Teknologi, dan Pendidikan Tinggi melalui Program Pengembangan Teknologi Industri TA 2019.

\section{Daftar Pustaka}

Abnisa, F., Wan Daud, W. M. A., Ramalingam, S., Azemi, M. N. B. M. and Sahu, J. N. (2013) 'Co-pyrolysis of palm shell and polystyrene waste mixtures to synthesis liquid fuel', Fuel, 108, pp. 311-318. doi: 10.1016/j. fuel.2013.02.013.

Abnisa, F., Arami-Niya, A., Wan Daud, W. M. A., Sahu, J. N. and Noor, I. M. (2013) 'Utilization of oil palm tree residues to produce bio-oil and bio-char via pyrolysis', Energy Conversion and Management. Elsevier Ltd, 76, pp. 1073-1082. doi: 10.1016/j.enconman.2013.08.038.

Asadullah, M., Anisur Rahman, M., Mohsin Ali, M., Abdul Motin, M., Borhanus Sultan, M., Robiul Alam, M. and Sahedur Rahman, M. (2008) 'Jute stick pyrolysis for bio-oil production in fluidized bed reactor', Bioresource Technology. Elsevier, 99(1), pp. 44-50. doi: 10.1016/j. biortech.2006.12.002.

BPPT (2019) Indonesia Energy Outlook 2019: The Impact of Increased Utilization of New and Renewable Energy on the National Economy.

Casoni, A. I., Bidegain, M., Cubitto, M. A., Curvetto, N. and Volpe, M. A. (2015) 'Pyrolysis of sunflower seed hulls for obtaining bio-oils', Bioresource Technology. Elsevier Ltd, 177, pp. 406-409. doi: 10.1016/j.biortech.2014.11.105.

Chattopadhyay, J., Pathak, T. S., Srivastava, R. and Singh, A. C. (2016) 'Catalytic copyrolysis of paper biomass and plastic mixtures (HDPE (high density polyethylene), PP (polypropylene) and PET (polyethylene terephthalate)) and product analysis', Energy. Elsevier Ltd, 103, pp. 513-521. doi: 10.1016/j.energy.2016.03.015.

Chen, W., Shi, S., Zhang, J., Chen, M. and Zhou, X. (2016) 'Co-pyrolysis of waste newspaper with high-density polyethylene: Synergistic effect and oil characterization', Energy Conversion and Management, 112, pp. 41-48. doi: 10.1016/j.enconman.2016.01.005.

Colapicchioni, V., Mosca, S., Guerriero, E., Cerasa, M., Khalid, A., Perilli, M. and Rotatori, M. (2020) 'Environmental impact of co-combustion of polyethylene wastes in a rice husks fueled plant: Evaluation of organic micropollutants and PM emissions', Science of the Total Environment. Elsevier B.V., 716, p. 135354. doi: 10.1016/j. scitotenv.2019.135354.

Exler, J. (2008) Chemistry of Polymers. 
Fadhil, A. B. (2017) 'Evaluation of apricot (Prunus armeniaca L.) seed kernel as a potential feedstock for the production of liquid bio-fuels and activated carbons', Energy Conversion and Management. Elsevier Ltd, 133, pp. 307-317. doi: 10.1016/j.enconman.2016.12.014.

Fadhil, A. B., Alhayali, M. A. and Saeed, L. I. (2017) 'Date (Phoenix dactylifera L.) palm stones as a potential new feedstock for liquid bio-fuels production', Fuel. Elsevier Ltd, 210, pp. 165-176. doi: 10.1016/j. fuel.2017.08.059.

Gavrilescu, D. (2008) 'Energy from biomass in pulp and paper mills', Environmental Engineering and Management Journal, pp. 537-546.

Green, D. W. and Perry, R. H. (2008) Perry's Chemical Engineers' Handbook. USA: The McGraw-Hill Companies, Inc.

Hwang, I. H., Kobayashi, J. and Kawamoto, K. (2014) 'Characterization of products obtained from pyrolysis and steam gasification of wood waste, RDF, and RPF', Waste Management. Elsevier Ltd, 34(2), pp. 402410. doi: 10.1016/j.wasman.2013.10.009.

Indonesian Pulp and Paper Association (2011) Indonesian Pulp \& Paper Industry Directory 2011. Jakarta.

Miandad, R., Barakat, M. A., Aburiazaiza, A. S., Rehan, M., Ismail, I. M. I. and Nizami, A. S. (2017) 'Effect of plastic waste types on pyrolysis liquid oil', International Biodeterioration and Biodegradation. Elsevier Ltd, 119, pp. 239-252. doi: 10.1016/j.ibiod.2016.09.017.

Mohan, D., Pittman, C. U. and Steele, P. H. (2006) 'Pyrolysis of Wood/Biomass for Biooil: A Critical Review', Energy Fuels, 20(3), pp. 848-889.

Monte, M. C., Fuente, E., Blanco, A. and Negro, C. (2009) 'Waste management from pulp and paper production in the European Union', Waste Management. Pergamon, 29(1), pp. 293-308. doi: 10.1016/J. WASMAN.2008.02.002.
Park, S. S., Seo, D. K., Lee, S. H., Yu, T. U. and Hwang, J. (2012) 'Study on pyrolysis characteristics of refuse plastic fuel using lab-scale tube furnace and thermogravimetric analysis reactor', Journal of Analytical and Applied Pyrolysis. Elsevier B.V., 97, pp. 2938. doi: 10.1016/j.jaap.2012.06.009.

Salan, T., Alma, M. H. and Altuntaş, E. (2019) 'The fuel properties of pyrolytic oils obtained from catalytic pyrolysis of non-recyclable pulper rejects using activated natural minerals', Energy Sources, Part A: Recovery, Utilization and Environmental Effects. Taylor \& Francis, 41(12), pp. 1460-1473. doi: 10.1080/15567036.2018.1548522.

Setiawan, Y., Purwati, S., Surachman, A., Wattimena, R. B. I. and Hardiani, H. (2014) 'Pelet Reject Industri Kertas Sebagai Bahan Bakar Boiler', Jurnal Selulosa, 4(02), pp. 57-64. doi: 10.25269/jsel.v4i02.87.

Setiawan, Y., Purwati, S., Surachman, A., Bastari I. W., R. and Pramono, K. J. (2016) 'Pemanfaatan plastik dari rejek industri kertas untuk bahan bakar', Jurnal Selulosa, 6(01), pp. 11-18. doi: 10.25269/jsel.v6i01.70.

Vamvuka, D. (2011) 'Bio-oil, solid and gaseous biofuels from biomass pyrolysis processesAn overview', International Journal of Energy Research, 35(10), pp. 835-862. doi: 10.1002/er.v35.10.

Xue, Y., Zhou, S., Brown, R. C., Kelkar, A. and Bai, X. (2015) 'Fast pyrolysis of biomass and waste plastic in a fluidized bed reactor', Fuel. Elsevier Ltd, 156, pp. 40-46. doi: 10.1016/j.fuel.2015.04.033.

Zeaiter, J. (2014) 'A process study on the pyrolysis of waste polyethylene', Fuel. Elsevier Ltd, 133, pp. 276-282. doi: 10.1016/j. fuel.2014.05.028. 